\title{
How health-conscious urban gardeners aim to increase vegetable consumption in their community while simultaneously supporting Black entrepreneurship
}

\author{
Rachel Soper* \\ California State University, Channel Islands
}

Submitted July 22, 2020 / Revised September 27 and November 1, 2020 / Accepted November 1, 2020 /

Published online March 22, 2021

Citation: Soper, R. (2021). How health-conscious urban gardeners aim to increase vegetable consumption in their community while simultaneously supporting Black entrepreneurship. Journal of Agriculture, Food Systems, and Community Development, 10(2), 413-430. https://doi.org/10.5304/jafscd.2021.102.023

Copyright $(2021$ by the Author. Published by the Lyson Center for Civic Agriculture and Food Systems. Open access under CC-BY license.

\begin{abstract}
While the food justice movement was initially associated with increasing availability of fresh produce in low-income communities of color through institutions such as farmers markets, scholars have critiqued this as imposing a right way of eating. Food justice scholarship has moved away from a focus on healthy eating toward a focus on community economic development, as food enterprises can stimulate job creation. This paper investigates the dual goals of the food justice movement through a case study in San Diego. While food justice has moved beyond promoting a love of produce and is increasingly oriented toward good jobs, for the urban gardeners in this study, the movement is still a lot about vegetables. They see food as medicine, and note the health benefits of moving toward a plant-based diet. Yet, they are reluctant to push this way of eating on others, as they do not want to
\end{abstract}

\footnotetext{
** Rachel Soper, Assistant Professor of Sociology, California State University, Channel Islands; One University Drive; Camarillo, California 93012 USA; rachel.soper@,csuci.edu
}

come across as elitist. Instead, they spread awareness that plant-based diets are an African tradition that should not just be associated with rich white folks. Rather than leading with nutrition, they lead with tradition, taste, and buying Black. To encourage consumption of vegetables, they aim to increase the supply of prepared food options in the community, and to market dishes as delicious rather than healthy, all the while supporting Black food entrepreneurs. When selling produce direct to the consumer through farmers markets does not achieve their vision of promoting health or supporting livelihoods, they re-imagine a strategy of promoting food justice through a neighborhood food supply chain.

\section{Keywords}

Food Justice, Health, Livelihood, Community

Garden, Urban Agriculture, Farmers Market

\section{Introduction and Literature Review}

As a scholarly concept, food justice intends to shed light on the racial injustices that mark our current 
model of food production, distribution, and consumption. At its core, it aims to bring attention to how the food system has been shaped by institutional racism-from unequal distribution of land, to lack of labor protections, to supermarket redlining. After critiques that food justice focused too much on urban landscapes, leaving out farm labor (Minkoff-Zern, 2014), recent scholarship has incorporated grocery retail and restaurant workers into the movement (Myers \& Sbicca, 2015; Sbicca, 2015, 2017; Sbicca \& Myers, 2017). Food justice is thus concerned with worker justice as well as equitable access to nutritious and culturally appropriate foods among communities of color, including Native American food deserts as well as inner city food apartheid (Smith, 2019). While food justice has expanded to examine wage labor in the food system, this paper pertains to food justice as it relates to addressing food apartheid in Black neighborhoods.

In previously redlined neighborhoods in U.S. cities, inhabited mostly by people of color, food options are sparse. With fewer grocery stores per capita and an abundance of liquor stores and fast food restaurants, it is difficult to find nutritious food. Indeed, "What are often assumed to be either 'natural' or unintentional patterns in urban development across space and time emerge as the products of powerful socio-spatial forces" (Lindemann, 2019, p. 869). Institutionally racist policies designed these urban landscapes, and to counteract them food justice organizations have developed community gardens and farmers markets to bring more fresh produce into otherwise barren areas to improve the local foodscape.

Alkon, Cadji, and Moore (2019) assert that "Since the early 2000s, a group of activists working under the banner of food justice have used food as a lens through which to create grassroots economic development and increase the health of lowincome communities of color" (p. 794). It is clear, then, that these are two key goals of the food justice movement: to stimulate community-based economic development on the one hand, and increase the health of low-income consumers on the other. But these two goals can be at odds, as the drive to increase income might necessitate selling to wealthier consumers outside of the neighborhood, thereby taking healthy food grown within the community away from those who need it most. This paper will explore that tension and investigate how a food justice organization in Southeastern San Diego reconciles these two competing goals.

\section{Food Justice as Access to Healthy Food}

Food justice is considered a branch of the environmental justice movement. Rather than confronting disproportionate exposure to environmental toxins such as landfills and polluting industries, it addresses disproportionate access to fresh food (Alkon \& Norgaard, 2009). Healthy food is an environmental good that should be equally distributed, and unhealthy foods are environmental burdens that no group should bear disproportionately. According to Alkon (2012), "food justice includes not only providing equal access to healthy food but also addressing structural inequalities in the food system and in the wider distribution of environmental benefits" (p. 12),

Food justice seeks to address diet-related illnesses among communities of color. Food justice activists focus on the injustice of disproportionate rates of diabetes in relation to the inaccessibility of fresh foods in the same way that environmental justice activists are concerned with the injustice of disproportionate rates of asthma in relation to proximity to polluting facilities (Alkon \& Norgaard, 2009). The injustice that food justice seeks to remedy is health-related: "people of color in low-income communities having higher rates of obesity and diabetes" (Guthman, 2014, p. 1153). Thus, increasing consumption of fresh fruits and vegetables in low-income communities of color in order to combat diet-related illnesses is a key goal of the food justice movement.

Food justice is thought to be the intersection of the environmental justice movement and the alternative food movement (Guthman, 2014). Food justice came about in response to the alternative food movement, which is predominantly white, middle-class, and exclusionary (Alkon, 2012). Food justice activists working in low-income communities of color draw on many of the same tools as the alternative food movement (Alkon et al., 2019). The same institutions connect growers 
to consumers, such as farmers markets, farm stands, community supported agriculture (CSA) harvest boxes, and health food stores. Other tools, such as community gardens and urban farms, improve the capacity of these neighborhoods to grow their own food. According to Alkon et al. (2019), the food justice movement has worked diligently to increase healthy food access in these places as activists "seek to address inequities in access to healthy food" (p. 794).

Food justice is a step in the right direction, compared to the alternative food movement, because it uncovers the institutional racism that has undergirded the food system and makes fresh produce more accessible to underserved communities. It is said to bring race, class, and culture back in, as the produce sold at farmers markets is more affordable and culturally appropriate than what is otherwise available through alternative food channels. "While these strategies are similar to marketing strategies employed by the local food movement," notes Smith, "they are re-imagined to provide for and support marginalized communities" (2019, p. 828). For example, a farmers market in a Black community would celebrate Black culture and offer traditional foods such as collard greens, okra, and black-eyed peas (Alkon, 2012).

Insofar as the goal is to bring healthy food into underserved areas, especially urban communities of color, to increase access to fresh fruits and vegetables and combat diet-related illnesses, these efforts are applauded for bringing fresh produce into spaces that are not exclusively white and affluent. However, these efforts are also critiqued for trying to convince others to eat healthier. Guthman refers to this as the "missionary impulse" (2011b, p. 268), or the civilizing mission to bring "good food" to others (2011b, p. 278). These institutions intend to bring healthy food to poor communities of color, and in doing so place a moral marker on eating fresh produce as an indicator of goodness. In the "moralist branch" of the food justice movement, "eating more kale, for example, can mark one's morality or sense of cultural distinction" (Bradley $\&$ Herrera, 2016, p. 101). Food choices are seen as signs of "heightened ethicality" (Guthman, 2011a, p. 141). As Bradley and Herrera state, "it is harmful to conflate dietary advice and morality," as "non- compliance with nutritional advice is seen as evidence of immorality" (2016, p. 102).

When initiatives to bring fresh produce to lowincome communities of color merely replicate the institutions of the alternative food movement, they do not necessarily receive the support of the communities they are trying to serve, because they are viewed as unwanted missionary projects. When University Extension staff developed a CSA for a nearby Native American tribe, there was a lack of participation because recipients felt that healthy eating was framed as a white behavior, in part due to the heavy presence of kale in weekly shares (Slocum \& Cadieux, 2015, p. 41). Through her undergraduate students' field studies with food justice organizations, Guthman found that "even some of the more race-conscious alternatives lack resonance in communities of color" (2011b, p. 265). Her students noted that project participants were indifferent or even hostile. A participant who did not opt in to buying below-market price fresh produce brought to their neighborhood in a mobile pantry noted the reason why as: "'Because they don't sell no food! All they got is birdseed. Who are they to tell me how to eat?"' (2011b, p. 273).

This missionary impulse also comes into play when food justice organizations develop workshops to teach people how to eat healthy. "Even though this food justice movement is far more race- and class-conscious than the mainstream alternative food movement," explains Guthman, "much of its on-the-ground work is more or less the same: educating people" (2011a, p. 154). Educating others about how to eat healthy assumes that there is a universal consensus on what kind of food and what way of eating is good (Alkon \& Agyeman, 2011). Guthman (2014) considers this to be universalizing the experiences of the dominant group and establishing it as the cultural norm. Slocum and Cadieux (2015) also advocate against the "targeting of nonwhite, poor, and female fat bodies for improvement through behavioral change" (p. 33). When "seemingly universal ideals do not resonate," explains Guthman (2011b, p. 268), "it is assumed that those for whom they do not resonate must be educated about these ideals."

Yet some African Americans perceive "healthy" food to be outside of Black culinary 
tradition (Rodman, Palmer, Zachary, Hopkins, \& Surkan, 2014). They believe that eating healthy will result in a loss of their heritage; they associate it with whites and do not want to conform to the dominant culture (Rodman et al., 2014). Based on the field notes of her students interning with food justice organizations, Guthman concludes that "the associations of the food, the modes of educating people to its qualities, and the ways of delivering it lack appeal to the people such programs are designed to entice" (2011b, p. 275). All in all, lowincome urban Black communities do not necessarily want fresh produce straight from the ground; they do not necessarily value it the way that project leaders do.

\section{Food Justice as Community Economic Development} While the food justice movement is critiqued for its emphasis on educating poor communities of color about eating healthy, another approach to the movement asserts that it is not just about food, but also community economic development. Food justice is not merely about spreading a love of produce; rather, the movement has been able to harness the cultural shift around increased consumption of local organic food to create jobs and income for underserved communities. Broad (2016) and Sbicca (2018) argue that food justice is not about food in and of itself anymore; it is about using food to advance social equity.

Food justice organizations should not just teach low-income communities of color "the right way to eat"; they should encourage "long-term community empowerment in historically oppressed neighborhoods," explains Broad (2016, p. 198). Similarly, Bradley and Galt assert that "In contrast to promoting exclusionary dietary recommendations, food justice can and should promote selfdetermination" (2014, p. 174), meaning job creation and local economic development.

These food justice initiatives establish training centers to cultivate business skills and work toward equitable livelihoods for communities of color through income-generating operations (Cadieux \& Slocum, 2015; Gottlieb \& Joshi, 2013). In one of the first books on food justice, Gottlieb and Joshi note that "community-based food enterprises can be a tool for economic development" (2010, p.
125). "One of the explicit goals of many of these programs is to create opportunities for people of color to work in the natural food industry," explain Alkon et al. (2019, p. 794).

Thus, food justice is not just about increasing the availability of fresh fruits and vegetables, it is also about economic development through market exchange. Yet, this emphasis on market-based change has been critiqued. Alkon (2012) notes that "The food justice approach is centrally about jobs and communities, and is inherently linked to the economic development and revival of communities and the creation of sustainable livelihoods" (p. 227). However, she also views it as "ironic that activists pursuing just sustainability would choose economic exchange as their strategy for reform" ( $p$. 13) and admits that the admirable work of food justice organizations is constrained by their adoption of market-based strategies. Agyeman and McEntee (2014) question how food justice can be both anti-racist and pro-market at the same time since "structural and institutional racisms are embedded in the market itself" (p. 216). They are critical of reforms that "perpetuate the idea that FJ and profit are compatible" (p. 218) and reject "the commoditization of food for profit" (p. 213).

Part of this critique of the food justice movement as market-based is related to absolving the state of its responsibilities to provide basic welfare. Alkon and Guthman (2017) argue that food justice organizations' strategy of alleviating food insecurity through the development and support of local food entrepreneurs is a poor substitute for direct assistance. McClintock (2014) also notes how the burden of food production and provisioning in low-income areas has largely shifted from the state to nonprofits and community-based organizations. According to Alkon (2012), "it simultaneously embodies a 'roll-back' of state responsibilities ... and a complementary 'roll-out' of market and civil society attempts to fill the state's responsibilities" (p. 13).

While the food justice movement is critiqued for being market-based and entrepreneurial, other scholars have found the entrepreneurial spirit of the movement to be rooted in an ethos of Black entrepreneurship. Lindemann (2019) found a "uniquely Black class consciousness among Black 
entrepreneurs" (p. 869). These entrepreneurs emerged out of a need to build amenities in their marginalized communities. She thus situates "entrepreneurialism as a way to fill an economic vacuum in otherwise economically and spatially marginalized neighborhoods" (p. 869). In her study, community residents spoke about entrepreneurialism as economic engagement for community benefit; it is an entrepreneurship based on community empowerment, to bolster Black economies (Lindemann, 2019, p. 870).

Indeed, Black food entrepreneurs build on "long-standing traditions of forming small-scale, culturally-rooted food provisioning businesses in order to provide sustenance to their own communities" (Alkon et al., 2019, p. 794). According to Lindemann (2019), Black entrepreneurship “is necessary in the face of a state and economy that have neglected, oppressed, and excluded Black communities." As McClintock (2014) asserts, "Existing critiques of urban agriculture's neoliberal nature can be counterproductive, amounting to throwing out the baby with the bathwater while failing to address the pressing needs on the ground" (p. 20). Even though they are marketbased, income-generating food justice initiatives support community development. However, because they are market-based, they may not support the initial objective of the movement.

Tension between Health and Economic Development: Healthy Food Sold to Those Outside the Community While increasing access to fresh produce in lowincome communities of color is certainly one of the goals of the food justice movement, and fostering income for residents through food-based businesses is another, it remains uncertain whether these goals are compatible or contradictory. Does working towards one undermine the other? According to some scholarship, there is tension between the community economic development approach and the combating health disparities through access to fresh produce approach, since consumers from outside the community have the capacity to pay more.

Fresh produce sold to the community can sometimes be more expensive than residents are willing to pay (Broad, 2016). Even though food justice projects tend to offer produce to their communities at subsidized costs, it remains more expensive than what could be purchased at a grocery store (Alkon \& Agyeman, 2011). One food justice enterprise found that their customers could get produce cheaper at the $99 \phi$ store; for US $\$ 15$, the cost of a CSA share, they could get $20 \%$ more produce at the $99 \notin$ store (Bradley \& Galt, 2014). Despite efforts to subsidize the cost of buying fresh local produce direct from producers, it often remains out of reach, putting food justice activists in the position of trying to convince low-income people to spend more money on food than they otherwise would (Alkon \& Agyeman, 2011). Thus, the availability of fresh produce in poor neighborhoods does not automatically lead to increased consumption. As a result, food justice initiatives have been critiqued for serving mostly people outside the community.

For example, the West Oakland farmers market mostly serves middle-class African American shoppers who live outside the neighborhood in more affluent parts of the city (Alkon, 2012), marking the "absence of low-income African Americans in whose interest the farmers market began" (p. 109). In addition, the Mandela Foods Cooperative in West Oakland provided an important source of income for its worker-owners, yet tended to draw a predominantly white customer base (Alkon, 2012, p. 108). As a result of local residents not valuing the fresh produce sold by them, the Bay Area-based food justice project Dig Deep developed relationships with high-end restaurants to negotiate high prices for their produce (Bradley \& Galt, 2014).

In these examples, the initiatives promote the food justice objective of community development while not necessarily increasing consumption of healthy food among residents. Although some might critique these endeavors for serving consumers outside the community that lacks access to fresh produce, others might applaud them for supporting the livelihoods of young people of color. Regarding Dig Deep selling their produce at a higher price to trendy restaurants in other parts of the city, Bradley and Galt say that "Condemning such engagements with high-end markets... would be too dismissive," because the food justice goal of 
community development is still supported: "decent jobs are fundamental components of larger scale structural changes central to the food justice vision" (2014, p. 179).

In order to stimulate job growth and economic development, marginalized and underserved community members must be able to make a return on the food they sell. On the other hand, in order for fresh produce to be more accessible to marginalized and underserved community members, it must be affordable. Markowitz (2010) calls this the "twin goal" of the food justice movement. It must simultaneously generate return for the vendor while also making produce affordable for low-income shoppers. However, the strategy of establishing farmers markets in low-income communities is complicated by the fact that the small farmers are themselves economically struggling (Markowitz, 2008). For Cadieux \& Slocum (2015), "those most marginalized by the current food system" should "take a leadership role in providing food for their own communities" (p. 5). Yet, those who are most marginalized deserve to receive fair economic return for providing food, and often that does not mean selling produce to others in their community who cannot afford to spend as much as consumers in more affluent parts of the city.

\section{Methods}

This paper addresses the tension between the health and community development goals of the food justice movement by exploring how urban community gardeners reconcile contradictory logics. According to Slocum and Cadieux (2015), "Part of the process of doing food justice is to determine the points where efforts toward the ideal get stuck, and what conditions enable them to keep going" (p. 30). Broad (2016) also points to how food justice is fraught with tension and "contrasting priorities" (p. 80). Rather than overly romanticizing complicated efforts, it is important to confront and unpack inconsistencies.

During 2014-2016, I volunteered with a food justice organization in San Diego. In addition to consulting on grant applications and taking minutes at community conversations, I tended a plot at the community garden. While I was there, a few occurrences stood out to me, that I perceived to be contradictory. One involved a community gardener who used his plot to grow sweet potatoes. He transformed the fresh produce into sweet potato pies and sold the baked good at a trendy farmers market in an affluent part of town. I became intrigued by this tension between generating revenue for Black farmers and vendors, and increasing the supply of fresh fruits and vegetables in a neighborhood suffering from food apartheid.

Is the overarching goal of the movement to get the produce grown in the neighborhood to people in the neighborhood who are at risk of suffering chronic health issues, or is the overarching goal to create jobs and generate income for the people who grow the food? What about economic development initiatives that stimulate income without a corresponding increase in consumption of fresh produce among the residents of the neighborhood that the program initially sought to assist? Is income to food entrepreneurs enough in and of itself, or does selling food outside the area defeat the purpose? This research project sought to explore that dilemma. A few years after moving out of the area to take a job as Assistant Professor, I returned to investigate this tension further through an additional month of field research in July 2019.

Village Produce ${ }^{1}$ is a food justice organization in the southeastern corner of the city of San Diego. This area of the city is historically Black. It was previously redlined and currently characterized as a food swamp, due to the lack of grocery stores and overabundance of liquor stores and fast food restaurants (Joassart-Marcelli, 2018). Village Produce is run by Wanda, who is a long-time community organizer in the neighborhood. Food justice organizations have been critiqued for being run by people from outside the community (Bradley \& Herrera, 2016; Broad, 2016; Cadieux \& Slocum, 2015; Lindemann, 2019; Pendergrast, Smith, Liebert, \& Benzer Kerr, 2019), but that is not the case with Village Produce. Wanda was active in the area, working toward community wellness, long before she established Village Produce's food justice agenda. Bradley and Herrera (2016, p. 102)

\footnotetext{
${ }^{1}$ The name of the organization and all respondent names are pseudonyms.
} 
note that leadership positions within the food justice movement have been colonized by welleducated white professionals, and Bradley and Galt (2014, p. 177) call for meaningful representation of and leadership by people of color in the movement.

This paper explores the perspectives of Black gardeners and food justice advocates in Southeastern San Diego (SESD). During one month of participant observation, I conducted audiorecorded loosely structured interviews with 20 urban gardeners. These participants were recruited through Village Produce at the weekly farmers market and during volunteer days at the community garden. ${ }^{2}$ I coded interview transcripts inductively, allowing the themes to emerge from the data. The findings presented below draw on a core group of Black gardeners who tend plots at the community garden. ${ }^{3}$ While I was interested in exploring health-livelihood tensions broadly, the specific themes of plant-based diet, African culinary traditions, not pushing healthy food on others, marketing taste not health, Black entrepreneurship, and being nonjudgmental came from the respondents themselves.

\section{Findings}

Food As Medicine: Plant-Based Diet

According to Randall, food justice means "adequate sensibility to healthy foods. Especially when we look at the health disparities." So eating healthy foods that are good for one's health and that combat diet-related illnesses is an essential component of food justice for these respondents: food justice is about health, and it is about food. Talking to community gardeners, it became clear that they see the people in their community dying of chronic conditions as a huge problem that could be preventable with better nutrition. Randall is concerned about the strokes and high blood pressure that are prevalent in his community and attributes these conditions in part to unhealthy diet. "A lot of us, in our younger days, we weren't eating correctly," he explains, but now he is committed to eating not just fresh produce, but raw organic produce. As Randall explains, "If I don't get organic into my body now, that's gonna be more pills I gotta buy later."

These health-conscious gardeners see food as medicine. The antidote, from their point of view, is eating more vegetables and less meat. One of the themes that came up again and again is plant-based diet. These gardeners are concerned with eating healthy, and eating healthy to them means eating a plant-based diet. Many of them are vegan, and even those who eat meat are dedicated to minimizing the amount of meat they eat and maximizing the amount of fresh fruits and vegetables.

Daryl has been vegan for 40 years. He was vegan before there was even a word for it. 1977 was the turning point for him, when he started moving away from a meat-based diet toward a plant-based diet. He started eliminating things from his diet, and his system responded well. He does not even eat much bread or wheat; he eats a lot of raw foods. Star is also vegan. As I interviewed her she was eating a grilled Portobello mushroom and seaweed sandwich with avocado and tomato on wheat bread. She grew up on a "slave diet," she explains, eating "pork, hamhawk, chitlins, bones: things that are high in fat and cholesterol, that are not good for you, that clog your arteries and give you all types of diseases." But she has "totally pulled away from that" and is "now focusing on health." "In order to keep yourself healthy, you have to be vegan," she continues, and "find products that are organic."

For several gardeners, their diets have changed as a result of major health complications. Cleo admits to eating poorly in her youth, but is vegan now because she thinks it is better for her health.

\footnotetext{
2 The garden is partially an allotment garden, where community members rent raised beds for $\$ 5$ per month, and partially an urban farm, where the garden manager leads volunteers to plant, water, and harvest produce to sell at the farmers market. In addition to tending their own plots, the community gardeners featured in this article also help Village Produce tend to the urban farm during community volunteer days, and are otherwise active in community events and vision-building conversations held by the food justice organization.

${ }^{3}$ All of the respondents quoted in the findings section are African American. Their ages range from early 30 s to late 60 s.
} 
At only 33, she has already suffered and overcome a serious health scare. She attributes her recovery to her change in diet: "Then I re-evaluated the things that I was putting into my body, and when I began my plant-based lifestyle, slowly it started to go away. Now I know the difference of how my body functions and feels having a plant-based diet."

Gardeners like Rhonda, Gladys, and Kelly are not currently vegan, but still value plant-based diets. Rhonda admits to challenges she has faced in her attempts to go vegan. Growing up, they had big pits in their back yard where they would roast whole animals. As an adult, she has tried to get away from that "ridiculousness." She has been vegan during periods of her life, but has never been able to stick with it because "chicken is always calling my name." Yet, she is still pursuing the goal of eating a plant-based diet. Her dream is to eat only what she grows. According to Rhonda, "Some people have to walk into the wall," for them to realize they need to make a change in the way they eat; and "People like me have to walk into the wall a couple times before they learn to go around it." She has struggled with giving up meat, even though she knows she feels better without it.

About whether or not she is vegan, Kelly replied that she is "not there yet ... in a dream I would be." Growing up, she was raised on $60 \%$ canned vegetables, and $40 \%$ fresh, yet "slowly but surely," she is moving away from canned goods and eating more fresh produce. Andre is not vegan, but he does try to minimize meat and maximize vegetables: "I'll do a small meat portion of fish or chicken and 4 or 5 vegetables, because I know at 55 years old, that's what my body needs. Eating vegetables is not a guarantee not to get cancer, diabetes, high blood pressure, stroke, but it helps the odds." This reaffirms that health is a driving force for most of the Black urban community gardeners in this study.

\section{African Culinary Tradition: Greens}

While eating a plant-based diet is important for the health of gardeners, they are also motivated by cultural tradition. Of special importance is collard greens. It is not just about eating fresh produce, but fresh produce that is culturally significant. For
Andre, his garden plot is very important to him because it allows him to grow collard greens for his mom. "We eat collard greens once a week in my family," he exclaims. "Collard greens, that's the southern tradition," explains Daryl, "that's really big, you get your braggin' rights on how you prepare it." He does not even cook collard greens, he eats them raw by chopping them up very finely and putting oil on to soften them up. Randall used to prepare collard greens with meat, but not anymore. "Back in the day I would use ham hock, pork, and all that seasoning, but I don't cook like that anymore."

"Greens are very important in Black culture," Star explains. "You take them and you fry them or you sauté them; some people boil them but that's really not the best way because you kill the nutrients." However, the greens that Star is talking about are not collard greens, but callaloo greens. In her plot, she is growing the African callaloo plant, which looks just like amaranth. The leaves are very popular in Jamaican and African cuisine, she asserts. And so the Black culture that she is referencing is not the soul food tradition of the Southern United States that others are nostalgic about, but the Black culture of Africa and its diaspora in the Caribbean.

Yet even though these gardeners are personally committed to eating more fresh produce and less meat because they think it is good for their health, and they see it as part of their culinary tradition, they are hesitant to push this way of eating on other people in their community because they realize that there is a negative connotation attached to healthy eating.

\section{Plant-Based Diet Not Just for Rich White Folks} While the gardeners in this study value a certain notion of healthy eating, they are careful not to be too dogmatic when spreading awareness. Others in the community, including their family and friends, are reluctant to give up meat and eat more plantbased because they associate veganism as a rich white person thing.

Plant-based diets "get a bad rap because it is associated with people who have money, so people who are poor, especially urban Black folks, they look at it and think 'that's something for rich 
people," explains Cleo, "I get that a lot: 'Veganism? That's rich white people stuff.' People are like, 'you don't even eat chicken anymore?! You're Black, you're supposed to eat chicken." For the people she is surrounded by, they associate Black culture with eating meat. She wants to spread awareness that not all Black cultures eat meat, and that there are plant-based diets in Africa. "It's a lack of understanding that tons of people eat plantbased diets across different cultures. People over here are like 'Black people don't eat plant-based' and I'm like where have you been, there are tons of Black people who eat raw vegan food."

When people say that being vegan, or eating a plant-based diet is a white people thing, Cleo's response is always, “Oh, I didn't realize that living healthier, living longer is only for privileged white folk." "When you convince somebody that what can be life changing and life altering and positive for them is negative, then you've colonized them," she continues. This association between eating healthy foods and affluent whiteness is a "stigma that is holding us back from learning to do something that can elevate us in so many ways."

According to Cleo, there is a misunderstanding of what parts are tradition. "People talking about the tradition of all-together food pots with everything stuffed in there, like ham hocks and all these different chitlins, people are like 'that's culture,' and then you realize: is it? Part of it is rooted in culture prior to colonization, but a lot of it is what we did on the slave plantation because we had nothing else. We had no other options, so we ate this junk." Cleo believes it is time to separate those two things: slow pot cooking is a tradition of west Africa which should be held on to, but "stuff like chitlins that have no nutritional value for us, that are bad for us" was the "have-to" necessity.

Star is also passionate about how the so-called traditional African American diet is a colonized diet. She notes that many people in their community were raised on a "slave diet," which consists of "a lot of meats, a lot of potatoes, a lot of pork, but it wasn't a lot of vegetables." The only vegetables that are traditional are eaten on holidays, like green beans and collard greens, but even then they are "stuffed with pork," she laments.
Rhonda also mentions how "a lot of our dietary history was from slavery," consisting of "scraps," of whatever was left over from the animal. "Of course, we make a dollar out of 15 cents: you give us intestines, we make chitlins; that is just mode of survival, what you have to do." She goes on to explain how people think that chronic health conditions are hereditary but it is not, "it's really your diet; it's not something that is in your family, it's just the culture that's carried on. ... When you come from a background where you weren't given the best choices, when you were given literally the scraps that were left, then you have to outgrow that legacy; you have to do away with that legacy and break that chain."

\section{Not Pushing Healthy Food on Others}

Outgrowing the legacy is complicated by the aversion of others to being told what to eat. While Daryl has been vegan since the 1970s, he is reluctant to preach about the benefits of veganism to others. He overheard a conversation once that has stuck with him. One of the stockers at a grocery store said to another: "You know who the worst ones are, these new vegetarians. They tryin' to convert everybody.' And I heard that. Even though they weren't talking to me, I needed to hear that." Because of this incident, he does not go around telling people about his diet. "If you don't say anything, I won't say anything. It's not about forcing people to change."

Star, another vegan, also takes a cautious approach. "You can't just tell people they are wrong. Because some people don't realize they've been living their whole life deficient from a lot of vitamins and minerals because they don't eat vegetables. They barely eat fruit. People are literally walking around with a lifetime of deficiency that is only going to catch up to them. It's hard to tell people 'you're not doing things right.' You have to have a certain way of doing it. And that takes a very sensitive process."

When Cleo tells people to go vegan, they pull back. "Especially for the Black community, you have to give it to them a little bit at a time, and let them process, let them choose what they want to do, not make them feel like they have to change completely and go right into eating no meat, no 
dairy," because then it will seem unattainable and out of reach.

Walter explains how certain villages in Africa eat vegan and organic, they just do not call it that. Plant-based diets have existed in other cultures, but rather than Black people associating their own African roots with plant-based diets, they label them as a "wealthy white person thing." And this is a huge hindrance to the movement, continues Walter, because then it seems elitist. "White people ... they gloat in that," he explains, "That's what Whole Foods and Jimbos is about. It's an 'I'm over here and you're down there' kind of thing."

Gladys, who is not vegan, does feel judgment from food-conscious people she knows from outside the garden. "When people say 'why aren't you vegan,' I do feel like they're making a judgment call. For them, it is not enough to give up meat and dairy. Once you are eating fruits and vegetables, then it is not enough unless they are also organic." She feels that this is an unattainable ideal. It is "not enough to be a plant-based consumer; it's like, 'that's not organic?! That means there's chemicals on that!' Even if you're eating a salad, it's full of chemicals."

For people she knows, especially those who are low-income, even if they try to eat healthier, if they feel that judgment that their non-organic salad is not good enough, then they'll give up on eating healthy altogether, because if they are going to be criticized for not being healthy enough, then why even take the baby steps in the first place. Their reaction is: "Forget it then, I'm just gonna do me. I cannot afford a $\$ 5$ head of lettuce,' so they'll forgo salad altogether and go back to the rotisserie chicken."

\section{Market Taste not Health: From Raw Produce to Prepared Food}

Because of this resistance to being told that the food one eats is not healthy enough, in order to get people in their community to eat more vegetables, respondents noted that you have to lead with flavor. Health is a motivating factor for most of the gardeners, yet rather than leading with nutrition education, this food justice organization seeks to spread awareness and appreciation that vegetables can actually taste good. According to them, the key is to lead with taste, not health. It is not about preaching to people that healthy food is what they should be eating, it is about opening their eyes and palates to dishes prepared with more vegetables and less meat.

Randall notes that it is hard to get customers to buy produce from the garden's farmers market stand when they can get it cheaper across the street at Food4Less. Community members will not spend more to get local organic produce at the farmers market, says Randall, "until you get them to realize it is healthier for them." But, "you can't come at that angle," he clarifies, regarding marketing the food grown at the garden as healthier.

Wanda, the director of Village Produce, has friends that "hate when people tell them what is good for them, what is healthy." They get mad, and say 'stop forcing healthy down my throat." "We can't shove that down their throat," explains Wanda, "We can't call things healthy, can't push a healthy agenda. At least not to my neighbors." Their "Gut reaction, when you say healthy food," she continues, is that they "don't want you to tell them what to do, what to eat, how to live."

Instead, her angle is to make food delicious first, then tell people that $80 \%$ of it is raw. But do not tell them it is raw from the start. "You have to lead with the deliciousness," explains Wanda, "Taste, that's how you market food to people." Randall also wants to teach his community that, depending on how you prepare them, vegetable dishes can taste good. "It's about changing habits, trying new things." If people who do not think they like vegetables taste them prepared a different way, they might become more accustomed to eating it.

Star takes a similar approach with her vegan catering company. She wants to repair the relationship between Black people and vegetables, but to do so, "you just gotta make it fun." And you have to give them choice and agency. "You gotta tell people: 'eat what you want, but taste this."' Her strategy is to take foods that people already love and turn them into vegan versions of the same dish. "It's all about getting people to taste it, because once people taste something, as long as it's good, it doesn't matter to them. So that's the trick that I use. It smells good so they can't help but go 
ahead and try it." Making healthy food delicious is her approach, "Because people think healthy means nasty and bland. And it doesn't. You can still eat delicious things, but they can be good for you."

"Even if you think people should be eating less meat, it's about the way you approach them," explains Gladys, like "Hey, have you ever tried this patty? Oh, this is great. I'll tell you what's it made of: I made it with only beets, blah blah. Oh, this is so great." According to her, it is important to offer people yummy things and focus on the positive, rather than make people feel bad for eating 'bad' food. "Let's find a way to share ideas in a nonjudgmental way about what we can do with our diets."

"A lot of the diet that we partake in as a culture is really slave food, so to provide that alternative is important," explains Rhonda. Rather than telling people what they should not be eating, offer them what they should. "We spend a lot of time talking about what is wrong, instead of providing what is right." She and her husband run a catering business, and their objective is to provide an alternative to the typical southern food diet that people will actually want to eat. They cook alternative foods that are culturally relevant but not as detrimental to your health, "so instead of mac ' $n$ cheese, it's cauliflower and cheese."

It can be seen, then, that rather than marketing fresh fruits and vegetables straight from the garden, Village Produce and its community gardeners who want to increase vegetable consumption in the Black community in SESD, think that the best way to do it is to offer prepared food options that taste good. Thus, this food justice organization is moving away from just selling raw produce direct from producer, to selling prepared food options. As it stands, selling fresh produce straight from the garden to neighborhood residents at farmers markets is not working, so they are developing other models to get neighbors to eat more vegetables while simultaneously stimulating economic growth and supporting the livelihoods of Black food entrepreneurs.

When I asked gardeners about whether they were interested in selling the produce they grow directly to consumers through the farmers market model, they were reluctant. About becoming a farmer, Calvin says, "It's not quite as easy as people think it is. If I can't give it away, I'm not gonna try to sell it." Calvin is a prolific gardener, yet his neighbors do not have a taste for the surplus vegetables he produces. Since he has so much difficulty giving it away, he is hesitant to dedicate the time and energy into setting up a market stand.

Rhonda, who is a teacher, talked about a student of hers who was interested in food justice and urban agriculture, but struggled to succeed. "She wasn't making it as a farmer," explained Rhonda, so she had to go outside of the community to sell produce because people weren't buying her produce in SESD. "Poor Black people aren't going to pay extra to buy vegetables from farmers markets down here because they don't even buy vegetables in the grocery store," says Star matter-of-factly. "It doesn't matter how much produce we have available" at the farmers market, laments market manager Wanda, "they don't buy it."

Rather than give up on the vision of spreading vegetables through their community, they have modified the vision to become more realistic. If people are not going to buy fresh produce directly from farmers, then offer them prepared food options instead. Offer them healthy versions of dishes they are already comfortable with. Rather than composting the abundance of produce that does not sell at the farmers market, whatever is left over could be cooked up and sold. "Showing people how you take it from A to B to C is important," says Rhonda. So simultaneously selling fresh produce directly to consumers, but also selling fresh produce to prepared food entrepreneurs who cook the produce and sell the ready-to-eat food to customers is her vision. Ideally, this is visually happening right in front of them, she continues, so they can reflect on where the ingredients are coming from: set up a table with fresh produce, then have another booth that cooks it on the spot. This not only creates more income-generating opportunities in the area, but it also facilitates the spread of healthy food.

Kelly has a similar vision, which she refers to as a flow chart. She envisions farmers market growers supplying food entrepreneurs with produce for them to prepare cooked food options. If 
ten people grow food, and ten people start restaurants, then they can be mutually beneficial to each other. Cooks need fresh herbs in their meals, she explains, and they would rather buy it fresh than to go Food4Less, so they can source it locally. "One just funnels right into the other," she gleefully exclaims.

Wanda calls this vision the 'neighborhood food supply chain.' It intends to offer healthier local food options, all the while creating income for people who grow, prepare, and sell food. An indicator of success would be an increased supply of produce in SESD, whether it is raw produce or prepared food. "We would like to work with and encourage people to be entrepreneurs in the food system. We see food as a career path," explains Wanda. In order to make food entrepreneurship a viable career path, it is important to spread awareness within the community about the importance of buying Black.

\section{Black Entrepreneurship: Get By but Give Back} According to Rhonda, entrepreneurship is "absolutely" part of food justice. She thinks it can be both about health and about entrepreneurship. Food justice means "eating healthy and supporting each other," according to Kelly. "We need to support Black business," she further asserts, "we need to educate our community on why it is important to shop here." Randall tells me that "some of the biggest talks I've had with people have been about supporting Black businesses." People at church look at him as if he is crazy when he says they need to support the people of the Black community when making purchases.

"Southeastern San Diego is a mixed economy," explains Wanda, "not everybody is poor, some people have purchasing power." To create a neighborhood food supply chain, she wants people who live in the neighborhood to use their purchasing power to buy from people in the neighborhood. When passersby at the farmers market complain that 99c store food is cheaper, the response should be, "it is going to cost a little bit more but it is benefiting Ms. so sand so, and you know her children." Wanda is adamant about getting people to spend their food dollars in the neighborhood instead of going outside the neighborhood to food shop: "People buy food every day; they've got to use their purchasing power for something." "One thing we do know, we all have to eat," says Randall, explaining that people do have purchasing power, and that money should go to entrepreneurs within the Black community.

There was a tremendous amount of respect in the urban gardening community for Black entrepreneurs-for people trying to make their food businesses work. They want people to put themselves out there to grow, cook, and otherwise create healthy food options to offer in the local marketplace, and for others to consciously use their purchasing power to buy from these local Black artisan entrepreneurs. Yet, when local purchasing power falls short, inevitably these Black food entrepreneurs will need to seek customers outside of SESD.

Respondents did not fault small Black businesses for selling their products in other parts of the city. Jamal, the former community gardener who sold his sweet potato pies at a popular farmers market in a trendy part of town and inspired my research question, recently opened up a soul food restaurant in another trendy neighborhood. His enterprise is located in a wealthy white community that previously established racial covenants barring non-whites from moving there (Joassart-Marcelli, 2018). The same zoning laws that greenlined and created exclusionary affluence there had redlined and created concentrated disadvantage in SESD. When I asked community gardeners how they felt about Jamal expanding his business, and whether he would still be considered under the umbrella of food justice, they defended him. Walter was initially on the fence, saying that his business was borderline food justice because while Black food entrepreneurs should be applauded, it would be better if he had set up his business in SESD. Then Cleo jumped in and said, "I feel like at the end of the day, you can't even try to judge that, because when everything is taken away from you, and you're given nothing, you have to think about your community, yes, but you also have to think about your extended family, your immediate family, and yourself."

Even if it does not perfectly fit their vision of food justice through a neighborhood food supply 
chain, they support Black food entrepreneur efforts to make a living for themselves. Cleo acknowledges that opening a business in SESD might not make enough business to stay afloat: "So if you go somewhere where people are actually going to keep your business running, you are doing that for you and your family." Yet, once that business is up and running, it is important to give back to the community: "If you can go there, make a storefront there, and make enough money to know that your business is sustainable, if you do that, you have to make sure to come back."

Walter ultimately agrees with Cleo and defends Jamal because "he's here and there." Even when he was selling his product at the other farmers market, he was here selling at this farmers market too. And that, according to Walter, and also Randall and Daryl, is evidence that he supports the community: by taking the time to sell his product in a poorer area that does not have as many food options when he could be maximizing revenue by only selling in affluent areas.

With regard to Jamal selling produce grown at the garden to people outside the community through his sweet potato pie stand at the popular farmers market in midtown, Randall says, "I understand it because that's how he makes his living." Even though he seemingly violated the food justice principle of using land and resources from within a low-income neighborhood of color to grow healthy, affordable, culturally appropriate food for the people of the neighborhood, fellow community gardeners did not see it that way. They defended him for trying to make a living, and justified selling to people outside the community as necessary to fully support one's livelihood; yet what really makes a difference, according to respondents, is also supporting their community by selling products within SESD.

Daryl defends Jamal also because he continued to sell at the SESD farmers market even though he was simultaneously selling at the popular farmers market. "My thing is this: he was growing food in the garden and using our venues to sell, but if you are in the business of selling, then you are going to find other venues. I don't see any injustice." Plus, he continues, when Jamal was at the garden, if somebody were to walk by and ask for some pro- duce, he would not hesitate to say "let me hook you up" and give it to them.

Besides selling product within SESD in addition to outside, other elements of giving back include providing jobs for people from the community and charging community members less than those from outside. "If you are going to start a business and it's not gonna be inside the community," explains Cleo, "the least you can do is hire folk who look like us, because if you are not offering the jobs to us, you are not giving back." Kelly's take is it's acceptable to sell products to people outside the community, in wealthier areas, as long as you charge them more. She thinks that it is important for people in SESD to use their money to buy from each other, yet she also thinks it is okay to sell outside the community as long as you charge people in SESD less for the same good.

Rhonda has students who are enthusiastic about starting healthy food businesses. I asked how she would get her students who want to sell their product in wealthier areas to also sell in SESD, and she responded: "You do both. We have a farmers market in this town every day of the week. Just because you go to Little Italy on Saturday doesn't mean you can't come to Southeast on Tuesday. You allow Little Italy to sustain you until Southeast builds up, until people get that education, until people understand the importance of it. You don't give up here. But you know that you have to eat, and your family has to eat. So you do go to Little Italy, you do go to Ocean Beach. You do all those places, but you still come back home."

Star, also a food entrepreneur who runs her own vegan catering business, similarly asserts that there is a delicate balance between being able to support oneself and also provide for the community. She is trying to promote herself to companies that cater lunches for their employees, so she is open to pursing business outside the community, but she would never do so completely. "I'm open to work with anybody but I mostly work in the community because that is where the need is." She is critical of people from the community who, in order to establish themselves, only cater to wealthy clientele in other areas: "To me that is somebody who is not as conscious to the lack in the community and doing things purely for a financial gain." 
She has to make a living for herself, but she is also motivated by the need to spread healthy food to her neighbors. "My business is for my community and it's also for profit," she explains, "But I don't handle my customers like I'm trying to squeeze every dime out of them, because I know these people, I know we're all in the same pot. We're all on the same level, trying to establish ourselves, being hundreds of years behind in the game."

There is a delicate balancing act when creating a local supply chain that simultaneously offers healthy food options in the community and facilitates Black entrepreneurship. Black entrepreneurs need to charge for their services, but not too much; and Black consumers need to be educated to spend a little more, to utilize their purchasing power to support Black business.

\section{A Nonjudgmental Approach to Food Justice: Every Angle at Once}

Rhonda practices an anti-extremist, baby steps approach to changing one's relationship with food. "It's a lot that we have to go through," says Rhonda, "It's not as simple as here's some kale. You have to go through a whole undoing." They have been conditioned to eat a certain way because that is what is available to them, and that is how they grew up eating. So unlearning what is cultural and what is tradition and then re-learning a new way of eating takes time. It is a gradual process and will not happen overnight: "There are levels to this. You have to start somewhere. You have to crawl before you walk."

I asked Rhonda to suppose that someone from the community eats Church's Chicken every day and does not otherwise get fresh fruits and vegetables in their diet; is it a win for the food justice movement if they go to Food4Less and starts eating salad, albeit a pre-packaged salad, not a salad made from the tomatoes and basil sold at the farmers market where we were standing. She said it was definitely a win: "Any time that you are showing progress, that you are going away from the Church's Chicken, then that's a start. Then we get you from over there [at the Food4Less] and we get you across the street here [at the farmers market], and that's another win, and then we get you to growing your own, and that's another." Any step in the right direction is a win, according to Rhonda, even if residents are not preparing meals from scratch from produce they grew themselves. Eating vegetables from a big box grocery store is better than not eating any vegetables at all. "It's progress. That's what I see as a win, because that extreme stuff is not sustainable."

Rhonda practices a nonjudgmental approach to food justice, because "people don't know what they don't know. You don't necessarily know that you need justice if it seems normal to you that you have a Jack in the Box on every corner." Although Village Produce gardeners are critical of the food swamp layout of their neighborhood, inundated with fast food restaurants and liquor stores, they do not judge their neighbors for eating at Jack in the Box; in fact, director and market manager Wanda regularly shows up at the farmers market with a Jack in the Box cup to keep herself hydrated. She asks passersby if they sell fried okra there and says in a relatable way, "I gotta check that out." For these food justice advocates, it is not about intimidating others with their foodie ethic, but meeting others where they are.

For Wanda, meeting others where they are could be as easy as if every fast food establishment were to put one vegetable on their menu: "You can put broccoli on anything. You can put broccoli on french fries with cheese." That would make progress in the right direction; it would increase the accessibility of vegetables in the area, even if vegetables are being accessed through a fast food restaurant rather than a farmers market or Black food enterprise. The approach to food justice in SESD is to come at it from every angle: get residents to eat more vegetables even if they are not grown locally and do not support Black food entrepreneurs, and simultaneously support Black food entrepreneurs even if the food is not sold locally and instead taps into a wealthier consumer base.

The dual goals of the movement might not be resolvable through the singular method of selling produce straight from the garden through a farmers market, but the same organization can work towards both goals simultaneously through different means. A variety of tactics can stimulate demand for vegetables: marketing taste not health, dispelling myths that a Black diet is a meat-based 
diet, offering prepared dishes rather than raw produce, and spreading awareness of the importance of supporting Black businesses. Meanwhile, another set of tactics can stimulate livelihood security for Black food entrepreneurs at different stages of the food chain through tapping into larger markets while still offering their goods to the community.

In this two-pronged approach, one end can generate revenue that supports Black food entrepreneurs even if food is not consumed within the community; at the other end, if those with processed meat-based diets start to integrate more vegetables-even if it is prepared food, not raw produce, and even if they get it from a supermarket not a farmers market-it is better than nothing. A prevailing discourse among these health-conscious community gardeners is that you have to meet people where they are and allow them to move at their own pace. As long as people are taking small steps to improve their relationship with fresh produce, it is progress. As long as Black livelihoods are being supported, even if they sell outside the community, it is progress. They are working towards both goals at once, but not necessarily in the same transaction. It is not about prioritizing one goal over another; it is about touching all angles at once.

\section{Conclusion}

There are two key goals of the food justice movement in Southeastern San Diego: to increase the availability of nutritious food options in the neighborhood that improve health, and to support the livelihoods of people from the community through Black food entrepreneurship. This paper set out to explore how food justice advocates reconcile the tension between improving the health of community members and supporting the livelihoods of Black entrepreneurs trying to establish themselves.

These health-conscious community leaders recognize the constraints holding people back from buying, preparing, and eating more vegetables. Rather than relying solely on the strategy of selling fresh produce straight from the garden to lowincome community members, they are working towards developing a neighborhood food supply chain, wherein urban gardeners supply Black food entrepreneurs with raw produce to create nutritious, culturally appropriate meals. Traditional dishes are re-made with less meat and more vegetables, in an effort to simultaneously support the health and livelihood of community members.

Yet, towards the goal of improving health, it is a win if community members start eating more vegetables, even if they are not purchased from Black food vendors. And, towards the goal of supporting livelihoods, it is a win if Black food entrepreneurs make a living for themselves, even if that necessitates selling outside of the community. Any step toward improving Black livelihoods through food entrepreneurship, even if they cater to affluent customers in historically white neighborhoods, and any step toward promoting health through spreading vegetables, even if it is fried okra from Jack in the Box, is a step in the right direction. These urban gardeners promote a nonjudgmental, anti-elitist food ethic that aims to meet people where they are rather than intimidating them by insisting that meals should be prepared by oneself from scratch with seasonal produce straight from the garden.

The food justice movement has been critiqued for being educational and entrepreneurial, yet these are key to urban community gardeners in SESD's food ethos. Only, rather than aspiring to educate the surrounding community about nutrition, they seek to spread awareness that vegetables taste good and that plant-based diets are part of their African heritage. The educational component is not that vegetables are good for you, but rather that vegetables are Black. Their vision of food justice is market-based-connecting growers to prepared food vendors to consumers through a neighborhood supply chain - but this entrepreneurial spirit is rooted in Black entrepreneurship and making consumer-based change not just through buying local, but buying Black.

The alternative food movement has long been considered white and exclusionary. Food justice is oriented toward racial and economic justice, yet "even those more race-conscious projects tend to get coded as white" (Guthman, 2011b, p. 275). The association between local organic produce and whiteness is so strong that even when efforts are made to distribute affordable, culturally appropriate food in low-income communities of color, it is perceived by the community as a "missionary 
impulse" to spread white cultural norms. The gardeners in SESD are aware of this connotation, so rather than trying to increase vegetable consumption through a discourse of "health," they aim to spread awareness that eating a plant-based diet is part of their African heritage: that eating more vegetables and less meat is not eating "white."

In breaking this association between healthy food and whiteness, and between Black culture and meat, gardeners know it has to be done in a delicate way. They do not want to come across as too preachy or off-putting. This demonstrates the "importance of a less messianic approach to food politics" (Guthman, 2011b, p. 264). The nonjudgmental food ethic of gardeners in SESD knows that changing eating habits is a gradual process that takes time, and steps. Realistically, neighborhood residents are not going to drop fast food and prepare all their meals from scratch from produce sold at the farmers market overnight. So, to meet residents where they are, Village Produce is transitioning from a farmers market model to a neighborhood food supply chain that offers more prepared food options.

These findings support the arguments made by Bradley and Galt (2014) in their work on food justice in the Bay Area. An important critique of food justice, they assert, is that it "often follows the mainstream food movement's lead, promoting certain ways of eating, usually centered around fresh and organic produce, in ways that are exclusionary" (2014, p. 174). Food justice activists in SESD are mindful of this, and work to spread healthier food options without the elitist component. Dig Deep, the organization that Bradley and Galt have studied, also attempts to counteract the valuation of certain foods as good and moral. "Dig Deep avoids imposing values about food on its crew members" (p. 178), who mostly subsist on fast food and soda, because "Eating cannot and should not be reduced to a simple binary of acceptable and unacceptable" (p. 182). According to Bradley and Galt, food justice practitioners should be more open, flexible, and anti-essentialist when it comes to food.

Not only do the food justice activists in their case study practice a nonjudgmental food ethic, but they also tap into high-end markets to bring revenue into their community: "Dig Deep is not waiting for a corporation or government to bring these jobs, but is instead trying to grow them itself, in part by accumulating capital from sales in highend markets" (Bradley \& Galt, 2014, p. 179). Bradley and Galt refer to this as the organization's "double logic" and "selective engagement with foodie logics" (p. 177). However, while food justice activists at Dig Deep partially and strategically engage with "foodie logics" that "stress the connection between diet and health" in order to generate revenue (p. 178), Village Produce's director and community gardeners are genuinely driven by the connection between diet and health. They wholeheartedly believe in food as medicine and are distraught that meat-based diets are wrecking the health of their loved ones. While Dig Deep is oriented toward job creation and economic development first and foremost, Village Produce attempts to combine the two by increasing vegetable consumption in the area while also promoting Black food entrepreneurs.

Increasing consumption of vegetables and increasing economic development in the area can happen simultaneously by using this multipronged approach that moves beyond the direct purchase of fresh fruits and vegetables model. Part of this strategy is supporting Black food businesses, and part of it is sneaking more vegetables into people's diets. Eventually, these two will hopefully marry harmoniously, with residents using their purchasing power, however limited, to buy vegetable-forward soul food from Black food vendors. In the meantime, however, any step toward increasing vegetable consumption and toward supporting Black livelihoods is progress toward achieving racial justice in a historically Black neighborhood.

\section{References}

Agyeman, J., \& McEntee, J. (2014). Moving the field of food justice forward through the lens of urban political economy. Geography Compass, 8(3), 211-220. https://doi.org/10.1111/gec3.12122

Alkon, A. H. (2012). Black, white, and green: Farmers markets, race, and the green economy. Athens: Georgia University Press. 
Alkon, A. H., \& Agyeman, J. (Eds.) (2011). Cultivating food justice: Race, class, and sustainability. Cambridge, MA: MIT Press. https://doi.org/10.7551/mitpress/8922.001.0001

Alkon, A. H., \& Guthman, J. (2017). Introduction. In A. H. Alkon \& J. Guthman (Eds.), The new food activism: Opposition, cooperation, and collective action (pp. 1-27). Oakland: University of California Press. https://doi.org/10.1525/california/9780520292130.001.0001

Alkon, A. H., \& Norgaard, K. M. (2009). Breaking the food chains: An investigation of food activism. Sociological Inquiry, 79(3), 289-305. https://doi.org/10.1111/j.1475-682X.2009.00291.x

Alkon, A. H., Cadji, Y. J., \& Moore, F. (2019). Subverting the new narrative: Food, gentrification and resistance in Oakland, California. Agriculture and Human Values, 36(4), 793-804. https://doi.org/10.1007/s10460-019-09954-x

Bradley, K., \& Galt, R. E. (2014). Practicing food justice at Dig Deep Farms \& Produce, East Bay Area, California: Selfdetermination as a guiding value and intersections with foodie logics. Local Environment, 19(2), 172-186. https://doi.org/10.1080/13549839.2013.790350

Bradley, K., \& Herrera, H. (2016). Decolonizing food justice: Naming, resisting, and researching colonizing forces in the movement. Antipode, 48(1), 97-114. https://doi.org/10.1111/anti.12165

Broad, G. M. (2016). More than just food: Food justice and community change. Oakland: University of California Press. https://doi.org/10.1525/9780520962569

Cadieux, K. V., \& Slocum, R. (2015). What does it mean to do food justice? Journal of Political Ecology, 22(1), 1-26. https://doi.org/10.2458/v22i1.21076

Gottlieb, R., \& Joshi, A. (2013). Food justice. Cambridge, MA: MIT Press.

Guthman, J. (2011a). Weighing in: Obesity, food justice, and the limits of capitalism. Oakland: University of California Press. https://doi.org/10.1525/9780520949751

Guthman, J. (2011b). 'If they only knew': The unbearable whiteness of alternative food. In A. H. Alkon \& J. Agyeman (Eds.), Cultivating food justice: Race, class, and sustainability (pp. 263-281). Cambridge, MA: MIT Press.

Guthman, J. (2014). Doing justice to bodies? Reflections on food justice, race, and biology. Antipode, 46(5), $1153-1171$. https://doi.org/10.1111/j.1467-8330.2012.01017.x

Joassart-Marcelli, P. (2018). Part 1: Historical background and current needs. The good food district: Report on needs, resources, priorities, and impacts. San Diego, CA: Project New Village, San Diego State University. https://fep.sdsu.edu/Docs/Report V3.pdf

Lindemann, J. (2019). Gardens and green spaces: Placemaking and Black entrepreneurialism in Cleveland, Ohio. Agriculture and Human V alues, 36(4), 867-878. https://doi.org/10.1007/s10460-019-09947-w

Markowitz, L. (2008). Produce(ing) equity: Creating fresh markets in a food desert. In G. De Neue, L. Peter, J. Pratt, \& D. C. Wood (Eds.) Hidden hands in the market: Ethnographies of fair trade, ethical consumption, and corporate social responsibility (pp. 195-211). Bingley, UK: Emerald Group. https://doi.org/10.1016/S0190-1281(08)28009-1

Markowitz, L. (2010). Expanding access and alternatives: Building farmers' markets in low-income communities. Food and foodways: Explorations in the history and culture of human nourishment, 18(1-2), 66-80. https://doi.org/10.1080/07409711003708512

McClintock, N. (2014). Radical, reformist, and garden-variety neoliberal: Coming to terms with urban agriculture's contradictions. Local Environmental, 19(2), 147-171. https://doi.org/10.1080/13549839.2012.752797

Minkoff-Zern, L.-A. (2014). Hunger amidst plenty: Farmworker food insecurity and coping strategies in California. Local Environment: The International Journal of Justice and Sustainability, 19(2), 204-219. https://doi.org/10.1080/13549839.2012.729568

Myers, J. S., \& Sbicca, J. (2015). Bridging good food and good jobs: From secession to confrontation within alternative food movement politics. Geoforum, 61(1), 17-26. http://dx.doi.org/10.1016/i.geoforum.2015.02.003

Pendergrast, T. L., Smith II, B. J., Liebert, J. A., \& Benzer Kerr, R. (2019). Introduction to the symposium: Rethinking food system transformation - food sovereignty, agroecology, food justice, community action and scholarship. Agriculture and Human V alues, 36(4), 819-823. https://doi.org/10.1007/s10460-019-09952-z

Rodman, S. O., Palmer, A. M., Zachary, D. A., Hopkins, L. C., \& Surkan, P. J. (2014). 'They just say organic food is healthier': Perceptions of healthy food among supermarket shoppers in Southwest Baltimore. Journal of Culture \& Agriculture, 36(2), 83-92. https://doi.org/10.1111/cuag.12036 
Sbicca, J. (2015). Food labor, economic inequality, and the imperfect politics of process in the alternative food movement. Agriculture and Human V alues, 32(4), 675-687. https://doi.org/10.1007/s10460-015-9582-2

Sbicca, J. (2017). Resetting the 'good food' table: Labor and food justice alliances in Los Angeles. In A. H. Alkon \& J. Guthman (Eds.), The new food activism: Opposition, cooperation, and collective action (pp. 107-132). Oakland: University of California Press. https://doi.org/10.1525/california/9780520292130.003.0005

Sbicca, J. (2018). Food justice now!: Deepening the roots of social struggle. Minneapolis: University of Minnesota Press. https://doi.org/10.5749/j.ctv3dnnrt

Sbicca, J., \& Myers, J. S. (2017). Food justice racial projects: Fighting racial neoliberalism from the Bay to the Big Apple. Environmental Sociology, 3(1), 30-41. https://doi.org/10.1080/23251042.2016.1227229

Slocum, R., \& Cadieux, K. V. (2015). Notes on the practice of food justice in the U.S.: Understanding and confronting trauma and inequality. Journal of Political Ecology, 22(1), 27-52. https://doi.org/10.2458/v22i1.21077

Smith II, B. J. (2019). Food justice, intersectional agriculture, and the triple food movement. Agriculture and Human V alues, 36(4), 825-835. https://doi.org/10.1007/s10460-019-09945-y 